\title{
Promoting Female Condom Use to Heterosexual Couples: Findings from a Randomized Clinical Trial
}

\author{
By Susan S. Witte, \\ Nabila El-Bassel, \\ Louisa Gilbert, \\ Elwin Wu, \\ Mingway Chang \\ and Jennifer Hill
}

Susan S. Witte is associate director, Nabila El-Bassel is director, Louisa Gilbert is codirector, Elwin Wu is assistant director and

Mingway Chang is statistician, all at the

Social Intervention Group, Columbia

University School of Social Work, New York. Jennifer Hill is assistant professor, School of International and Public Affairs, Columbia University.

CONTEXT: The female condom remains the only female-initiated method for preventing pregnancy and STDs, including HIV. Innovative methods for promoting its use, and for involving male partners in its use, are needed.

METHODS: A sample of 217 women and their main male sexual partners were randomly assigned to one of three study conditions: a six-session relationship-based STD prevention intervention provided to the couple together, the same intervention provided to the woman only or a single-session education control provided to the woman only. Assessments were conducted at baseline and three months postintervention. Contrast coding was used to examine whether the effects of the two active interventions differed from those of the control intervention, and whether the effects of the two active interventions differed from each other. Regression analyses were used to estimate treatment effects.

RESULTS: During follow-up, participants in either active intervention were more likely to use a female condom with their study partner and with all partners, and used female condoms at a higher rate with all partners, than individuals assigned to the control intervention; at the end of three months, they were more likely to intend to use the condom in the next 90 days. No significant differences in outcomes were found between the active intervention groups.

CONCLUSIONS: Focusing on both a woman and her main male sexual partner is efficacious in increasing female condom use and intention to use among heterosexual couples at risk for HIV and other STDs.

Perspectives on Sexual and Reproductive Health, 2006, 38(3):148-154

Important gender-based innovations in the prevention of HIV and other STDs include the introduction of the female condom and promoting its use in interventions that target couples. ${ }^{1}$ In the face of soaring heterosexually acquired HIV infection globally, the female condom has emerged as an acceptable alternative or supplemental barrier method to the male condom. ${ }^{2}$ The preventive effectiveness of the female condom against STDs appears comparable to that of the male condom, ${ }^{3}$ few (if any) adverse reactions have been reported among women who have tried the product and use of the device lowers the risk of bacterial and viral infections. ${ }^{4}$

In the United States, HIV prevention intervention trials introducing the female condom have demonstrated increases in reported use among a range of populations: urban women attending family planning clinics, women attending STD clinics, women in methadone maintenance treatment and women exchanging sex for drugs or money. ${ }^{5}$ To date, however, no studies using a randomized clinical trial design have either tested the efficacy of a relationship-based intervention on the use of the female condom among women and their long-term male sexual partners or compared two strategies for introducing the device. Previous research has demonstrated promise in increasing female condom use within stable partnerships, ${ }^{6}$ and some evidence suggests that HIV prevention interventions designed to assist women in engaging their male sexual partners in female condom use may be particularly effective. ${ }^{7}$ More re- search is needed on whether involvement of male partners in the introduction of the device leads to increased use. ${ }^{8}$

The purpose of this article is to examine female condom use outcomes among 217 women and their main male sexual partners (434 male and female participants) during a three-month follow-up period in Project Connect, a randomized clinical trial of a six-session relationship-based HIV/STD prevention intervention. The principal outcome in the parent study ${ }^{9}$ was reduction in unprotected vaginal intercourse (including both male and female condom use), assessed three and 12 months postintervention. The main finding was that relative to participants in the control group, women and men assigned to the six-session intervention were more likely to report a reduction in the number of episodes of unprotected vaginal intercourse. No significant differences were observed according to whether couples received the intervention together or the woman received it alone.

In the present study, the four outcomes on which we focus are any female condom use, number of female condoms used, female condom use intentions and female condom use outcome expectancies (defined as beliefs about the likelihood of positive or negative outcomes occurring as a result of engaging in female condom use). Outcomes are examined with regard to the participant's study partner alone and all sexual partners. We addressed two research questions: Did the active intervention (whether provided to the couple together or the woman only) promote significantly greater improvements in outcomes than the 
control intervention? And did providing the intervention to couples together promote significantly greater improvements in outcomes than providing it to women alone?

\section{METHODS}

\section{Study Design}

The design of Project Connect, conducted between 1997 and 2001, is described fully elsewhere, ${ }^{10}$ but summarized briefly here. All elements of the study protocol were reviewed and approved annually by the institutional review boards at the study site and research institution.

Women were recruited from an outpatient clinic facility at a New York hospital providing a range of primary health care and social services. A woman was eligible for Project Connect if she was 18-55 years old; had a male sexual partner whom she identified as a boyfriend, spouse or lover; was in a long-term relationship (i.e., had been involved with this partner for the past six months and intended to stay with him for at least one year); had had at least one episode of unprotected vaginal or anal sex with this partner in the past 30 days; did not report any life-threatening abuse by this partner within the past six months (according to selected questions from the Revised Conflict Tactics Scales); ${ }^{11}$ and was a patient at any of the hospital's outpatient clinics. To be eligible, a woman also had to know or suspect that her partner met at least one of the following STD risk criteria: He had had sex with other men or women in the past 90 days, he had had an STD diagnosed or exhibited symptoms of an STD in the past 90 days, he had injected drugs in the past 90 days or he was HIV-positive. Of the 388 screened women who were eligible for the study, 217 (56\%) successfully recruited their regular male sexual partners and were included in the study. ${ }^{12}$

Prior to the baseline interview, all participants provided informed consent. Couples completed face-to-face baseline assessment interviews simultaneously but separately, with gender-matched interviewers. They were then randomly assigned to one of three study groups. In the first group, both the woman and her partner attended six weekly relationship-based sessions ( $\mathrm{N}=81$ couples). In the second, only the woman attended the six weekly sessions ( $\mathrm{N}=73$ couples). In the third, which served as the control group, only the woman attended one STD information session ( $N=63$ couples). The group sizes differed because during a regular review of scientific integrity, we determined that a few random assignment envelopes had been omitted accidentally. We controlled for the effect of across-group differences, a potential result of this imbalance, in the analyses. All women and men were asked to return for a followup assessment three months postintervention.

Step-by-step details for the Project Connect intervention sessions were provided in manuals that guided facilitators in what to say and what to do as they completed each session activity. In the couples sessions, the facilitator provided coaching and feedback, and encouraged couples to roleplay and engage with each other. In the women-only sessions, the facilitator played the role of a woman's partner, or took on a woman's role as she played her partner's role, thus creating opportunities for her to practice. Sessions centered on the woman and her recruited partner, with a strong emphasis on the relationship, including how issues like intimacy, closeness, monogamy and trust can act as barriers to condom use. The intervention emphasized the importance of communication, negotiation and problem-solving skills, and highlighted how relationship dynamics may be affected by gender roles and expectations.

Use of the female condom was introduced in the fourth session, along with a review of male and female anatomy and an introduction to male condom use skills. All participants were shown a brief video on female condom application, and then a live demonstration of correct placement on a pelvic model. In the couples sessions, both the woman and her partner practiced proper insertion and removal of the device on a pelvic model; in the women-only sessions, women practiced on the pelvic model and had the opportunity to role-play introducing the device and its use to their partner, played by the facilitator. The advantages and disadvantages of the device from both male and female perspectives were presented and discussed. Many participants set a goal to use the female condom with their main partner between the fourth and fifth intervention sessions. Each participant received three female condoms at the end of every session. Thus, depending on the number of attended sessions, participants could receive between zero and 18 female condoms.*

The single STD education control session lasted one hour and was provided immediately following randomization. Participants were shown a videotape (available in English and Spanish), ${ }^{13}$ which included a discussion and demonstration of female condom use, that was followed by a brief question-and-answer period. Participants did not receive female condoms, but received information from both the videotape and the facilitator about where they could purchase the device (at a local pharmacy) or how to obtain it for free (from New York City Department of Health STD clinics, from the obstetrics-gynecology clinic within the study setting or by getting a fiscal order from their physician or nurse practitioner, to be reimbursed by Medicaid).

\section{Measures}

Baseline and three-month follow-up interviews included questions on social and demographic characteristics, STD sexual risk behaviors, HIV status and outcomes of interest. Participants were asked to report, for study partners and casual partners, whether a female condom was used during an act of vaginal intercourse, the number of acts of vaginal intercourse protected by female condoms (continuous) in the past 90 days and whether they intended to use the female condom in the next 90 days. The interview also included 18 items from a scale assessing three categories of female condom use outcome expectancies: physical, social

*Participants assigned to the six education sessions were also given male condoms at the end of every session. 
TABLE 1. Percentage of participants in a trial of a female condom promotion intervention, by selected baseline characteristics, according to gender and intervention group, New York City, 1997-2001

Characteristic

\begin{tabular}{ll} 
Female & \\
$\begin{array}{l}\text { Couples } \\
(\mathrm{N}=81)\end{array}$ & $\begin{array}{l}\text { Women- } \\
\text { only } \\
(\mathrm{N}=73)\end{array}$ \\
\hline 9.9 & 8.2
\end{tabular}

\begin{tabular}{|c|c|c|c|c|c|c|}
\hline Age $<25$ years & 9.9 & 8.2 & 9.5 & 7.4 & 9.6 & 7.9 \\
\hline Black & 54.3 & 54.8 & 54.0 & 48.1 & 61.6 & 55.6 \\
\hline Hispanic & 38.3 & 43.8 & 36.5 & 42.0 & 31.5 & 39.7 \\
\hline High school/GED & 42.0 & 37.0 & 55.6 & 44.4 & 61.1 & 54.0 \\
\hline Never-married & 67.9 & 57.5 & 52.4 & 56.8 & 54.8 & 54.0 \\
\hline Employed & 11.1 & 15.1 & 17.5 & $24.7^{*}$ & $45.2^{*}$ & $34.9^{*}$ \\
\hline \multicolumn{7}{|l|}{ Annual income } \\
\hline$<\$ 5,000$ & 64.2 & 72.6 & 68.3 & 56.3 & 46.6 & 47.6 \\
\hline$>1$ partner $\neq$ & 24.7 & 23.3 & 14.3 & 13.6 & 16.4 & 12.7 \\
\hline Ever tested for HIV & 95.1 & 91.8 & 92.1 & 92.6 & 80.8 & 90.5 \\
\hline HIV-positive & 25.9 & 21.9 & 15.9 & $29.6^{*}$ & $16.4^{*}$ & $11.1^{*}$ \\
\hline HIV status unknown & 6.2 & 11.0 & 7.9 & $8.6^{*}$ & $19.2^{*}$ & $9.5^{*}$ \\
\hline No condom use $\neq$ & 64.2 & 71.2 & 76.2 & 69.1 & 69.9 & 79.4 \\
\hline \multicolumn{7}{|l|}{ Used noninjection } \\
\hline drugsł & 60.8 & 63.8 & 44.6 & 59.2 & 67.1 & 63.9 \\
\hline Used injection drugsł & 11.1 & 5.5 & 6.3 & 12.5 & 5.5 & 4.8 \\
\hline Ever had STD & $69.1^{*}$ & $60.3^{*}$ & $47.6^{*}$ & 56.8 & 60.3 & 49.2 \\
\hline Had STD symptom‡ & 50.6 & 57.5 & 42.9 & 11.1 & 2.7 & 11.1 \\
\hline \multicolumn{7}{|l|}{ Couple HIV status } \\
\hline Both HIV-negative & 51.9 & 49.3 & 61.9 & na & na & na \\
\hline Both HIV-positive & 19.8 & 12.3 & 4.8 & na & na & na \\
\hline HIV-discordant & 14.8 & 12.3 & 17.5 & na & na & na \\
\hline Unknown & 13.6 & 26.0 & 15.9 & na & na & na \\
\hline
\end{tabular}

*Differences across groups are significant at $p<.05$. +Percentages are for the male partners of the women in this group. ¥In past 90 days. Notes: Calculations are based on the complete data; a few variables are missing data for up to $6 \%$ of participants. na=not applicable. and self-evaluative. Items in the physical category included "I am comfortable using the female condom" and "I believe that I can make female condom use fun and erotic"; in the social category, "I am embarrassed to ask my partner to use the female condom" and "I encourage my friends to use the female condom"; and in the self-evaluative category, "the female condom gives me more personal control over birth control" and "the female condom gives me more options for protection." Each item was scored on a Likert scale from 1 (strongly disagree) to 5 (strongly agree); the final measure was the sum of the 18 scores (possible range, 18-90, with higher scores indicating stronger endorsement of positive outcome expectancies of female condom use). The measure has an internal consistency reliability of $0.80 .{ }^{14}$ Interview staff used a 90-day calendar to help participants recall events during this time frame.

\section{Analysis}

We used an intention-to-treat approach to estimate treatment effects. This approach requires that all participants be included in the analyses, including those who did not complete sessions or follow-up assessments. The followup rates for the couples, women-only and control groups were $86 \%, 84 \%$ and $79 \%$, respectively. In the couples group, the overall session completion rate was 54\%; in the womenonly group, $64 \%$. At session four, in which the female condom was introduced, $59 \%$ and $71 \%$ of the participants assigned to the couples and women-only groups attended. In t tests of bivariate association, attendance in the two active intervention groups was not determined to be significantly different. Levels of missing outcome data vary by group and outcome, ranging from 14\% (on number of sexual partners for participants in the couples group) to $22 \%$ (on number of unprotected acts for participants in the control group).

In chi-square tests of association, several differences at baseline were found between those who were available for follow-up and those who were not. For participants assigned to the control group, women available for follow-up were less likely to be employed, more likely to have made more than \$5,000 in the last year and more likely to have used noninjection drugs in the prior 90 days than women not available for follow-up; they also had fewer instances of unprotected sex. Men available for follow-up; reported fewer instances of unprotected sex than men unavailable for follow-up; they In the women-only group, participants who provided follow-up data were less likely to have completed high school or have a GED than women not available for follow-up. These differences argue against using a complete case approach to the missing outcome data because it requires the assumption that no such differences exist. We employed multiple imputation ${ }^{15}$ to handle missing values; the imputation procedure was performed using Stata 9.0 with a user-written program. ${ }^{16}$

We conducted t tests to examine the difference in means among the primary outcomes. We used contrast coding to examine whether the effects of the two active interventions differ from those of the control intervention, and whether the effects of the two active interventions differ from each other. Contrast coding involves combining variables into

\begin{tabular}{|c|c|c|c|c|c|c|}
\hline \multirow[t]{2}{*}{ Outcome } & \multicolumn{2}{|l|}{$\begin{array}{l}\text { Couples } \\
(\mathrm{N}=162)\end{array}$} & \multicolumn{2}{|c|}{$\begin{array}{l}\text { Women-only } \\
(\mathrm{N}=146)\end{array}$} & \multicolumn{2}{|l|}{$\begin{array}{l}\text { Control } \\
(\mathrm{N}=126)\end{array}$} \\
\hline & Baseline & Follow-up & Baseline & Follow-up & Baseline & Follow-up \\
\hline \multicolumn{7}{|l|}{$\%$ ever used in past 90 days } \\
\hline With study partner & $2.47(1.22)$ & $22.59 *(3.38)$ & $5.62(1.94)$ & $25.48^{*}(3.82)$ & $3.97(1.75)$ & $11.59(2.97)$ \\
\hline With all partners & $3.09(1.36)$ & $23.21(3.55)$ & $7.67(2.24)$ & $27.12^{*}(3.86)$ & $3.97(1.75)$ & $13.49(3.12)$ \\
\hline \multicolumn{7}{|l|}{ Mean no. of uses in past 90 days } \\
\hline With study partner & $0.04(0.02)$ & $0.69(0.18)$ & $0.10(0.04)$ & $0.96^{*}(0.29)$ & $0.06(0.03)$ & $0.30(0.10)$ \\
\hline With all partners & $0.06(0.03)$ & $0.72(0.18)$ & $0.15(0.05)$ & $1.10 *(0.33)$ & $0.06(0.03)$ & $0.33(0.10)$ \\
\hline$\%$ intending to use in next 90 days & $30.86(3.64)$ & $43.58^{*}(3.98)$ & $35.62(3.98)$ & $42.88^{*}(4.55)$ & $26.19(3.93)$ & $27.46(4.98)$ \\
\hline Mean outcome expectancies† & $59.43^{*}(0.63)$ & $60.75^{*}(0.80)$ & $57.93(0.68)$ & $59.49(0.86)$ & $56.96(0.75)$ & $57.74(0.83)$ \\
\hline
\end{tabular}




\begin{tabular}{|c|c|c|c|c|c|c|}
\hline Outcome & $\begin{array}{l}\text { Intervention } \\
\text { (vs. control) }\end{array}$ & $\begin{array}{l}\text { Couples (vs. } \\
\text { women-only) }\end{array}$ & $\begin{array}{l}\text { Baseline } \\
\text { measurement } \\
\text { of outcome }\end{array}$ & Male & $\begin{array}{l}\text { HIV-positive (vs. } \\
\text { HIV-negative) }\end{array}$ & $\begin{array}{l}\text { HIV status } \\
\text { unknown (vs. } \\
\text { HIV-negative) }\end{array}$ \\
\hline \multicolumn{7}{|l|}{ Ever used in past 90 days $†$} \\
\hline With study partner & $\begin{array}{l}4.06^{*} \\
(1.24-13.35)\end{array}$ & $\begin{array}{l}1.13 \\
(0.44-2.91)\end{array}$ & $\begin{array}{l}10.67^{* *} \\
(2.34-48.71)\end{array}$ & $\begin{array}{l}1.17 \\
(0.58-2.38)\end{array}$ & $\begin{array}{l}0.98 \\
(0.40-2.44)\end{array}$ & $\begin{array}{l}1.25 \\
(0.33-4.67)\end{array}$ \\
\hline With all partners & $\begin{array}{l}3.57^{*} \\
(1.11-11.54)\end{array}$ & $\begin{array}{l}1.03 \\
(0.40-2.66)\end{array}$ & $\begin{array}{l}6.06^{*} \\
(1.21-30.35)\end{array}$ & $\begin{array}{l}1.27 \\
(0.64-2.51)\end{array}$ & $\begin{array}{l}0.93 \\
(0.35-2.45)\end{array}$ & $\begin{array}{l}1.97 \\
(0.60-6.41)\end{array}$ \\
\hline \multicolumn{7}{|l|}{ No. of uses in past 90 daysł } \\
\hline With study partner & $\begin{array}{l}4.33^{*} \\
(1.38-13.58)\end{array}$ & $\begin{array}{l}1.38 \\
(0.55-3.45)\end{array}$ & $\begin{array}{l}2.33 \\
(0.92-5.91)\end{array}$ & $\begin{array}{l}1.10 \\
(0.56-2.17)\end{array}$ & $\begin{array}{l}0.98 \\
(0.40-2.36)\end{array}$ & $\begin{array}{l}1.18 \\
(0.37-3.81)\end{array}$ \\
\hline With all partners & $\begin{array}{l}3.73^{*} \\
(1.32-10.54)\end{array}$ & $\begin{array}{l}1.39 \\
(0.53-3.65)\end{array}$ & $\begin{array}{l}1.70 \\
(0.73-3.96)\end{array}$ & $\begin{array}{l}0.97 \\
(0.43-2.22)\end{array}$ & $\begin{array}{l}0.90 \\
(0.37-2.20)\end{array}$ & $\begin{array}{l}1.81 \\
(0.66-5.00)\end{array}$ \\
\hline Intend to use in next 90 days $†$ & $\begin{array}{l}2.20^{*} \\
(1.12-4.32)\end{array}$ & $\begin{array}{l}1.16 \\
(0.61-2.20)\end{array}$ & $\begin{array}{l}2.61^{* *} \\
(1.48-4.59)\end{array}$ & $\begin{array}{l}1.18 \\
(0.74-1.88)\end{array}$ & $\begin{array}{l}1.21 \\
(0.61-2.39)\end{array}$ & $\begin{array}{l}1.07 \\
(0.48-2.37)\end{array}$ \\
\hline Outcome expectancies§ & $\begin{array}{c}1.76 \\
(-0.28 \text { to } 3.80)\end{array}$ & $\begin{array}{l}0.79 \\
\text { (-1.40 to } 2.99)\end{array}$ & $\begin{array}{l}0.44^{* *} \\
(0.32-0.57)\end{array}$ & $\begin{array}{l}0.07 \\
(-1.67 \text { to } 1.81)\end{array}$ & $\begin{array}{l}-0.42 \\
(-2.70 \text { to } 1.85)\end{array}$ & $\begin{array}{l}-2.14 \\
(-5.13 \text { to } 0.85)\end{array}$ \\
\hline
\end{tabular}

${ }^{*} \mathrm{p}<.05 .{ }^{* *} \mathrm{p}<.01$. Odds ratios from logistic regression. ‡Incidence rate ratios from negative binomial regression. $§$ Coefficients from ordinary least squares regression. Notes: All models include random effects estimates. Figures in parentheses are $95 \%$ confidence intervals.

subsets for the purpose of direct comparison. Numerically, the sum of the codes must equal zero. Two contrast codes were created. First, to test whether the six-session active intervention (delivered either to couples or to women only) was efficacious compared with one education session, we numerically weighted the two treatment groups so that their additive value plus the value given the control group equaled zero: one-third, one-third and negative two-thirds, respectively. Second, to test whether the intervention was more efficacious when the woman and her partner received it together or when the woman received it alone, we coded the couples, women-only and education control groups onehalf, negative one-half and zero, respectively.

Quantitative estimates of treatment effects relied on ordinary least squares regression for female condom use outcome expectancies, logistic regression for female condoms use in the past 90 days and intention to use female condoms, and negative binomial regression for the number of female condoms used during vaginal intercourse in the past 90 days. ${ }^{17}$ The unit of analysis was the individual; however, because reports from partners constituting a couple were not independent of each other, and would be highly correlated, random-effects estimates, ${ }^{18}$ which accommodate within-group correlation structures, were used. In this case, the random effects were incorporated into the ordinary least squares, logistic and negative binomial regression models, which allow responses within a couple to be correlated but assume independence across couples. Further, inclusion of theoretically important variables related to HIV risk behavior in regression models can result in estimates of treatment effects with smaller standard errors ${ }^{19}$ and can illuminate associations between the outcomes and critical background characteristics. Thus, baseline measures of outcome variables were included in the regression equations, since these are highly likely to be correlated to reports at follow-up. In addition, gender and HIV status were included because they are associated with differential outcomes for HIV prevention interventions. ${ }^{20}$ All estimates were obtained using Stata version 9.0.

\section{RESULTS}

Participants across the three study groups were similar on demographic characteristics and HIV risk behavior (Table $1)$. The majority of the women and their partners were more than 25 years old. The majority of participants were black, and most of the rest were Hispanic; more than half were never-married. Roughly 40-60\% of participants across all study groups had at least a high school level of education; fewer than half were employed, and more than half had low income levels. A higher proportion of women than of men reported having multiple sexual partners within the prior 90 days. The high prevalences of reporting a lifetime history of STD and no condom use in the past 90 days indicate that these couples engaged in HIV risk behaviors. The only significant differences are for employment and HIV status among men, and for STD experience among women. The sample included HIV-negative, HIV-positive and HIVdiscordant couples.

At the bivariate level, participants in both active interventions had significantly higher rates of ever-use of the female condom during follow-up and significantly greater intentions to use it in the next 90 days than did those in the control group (Table 2). Compared with women in the control group, participants in the couples group also reported greater outcome expectancies, and participants in the women-only group reported more uses of the female condom during follow-up. Patterns of female condom use with a study partner were consistent with reported use with all partners. Participants in the women-only group reported a higher average number and rate of female condom use dur- 
ing follow-up than participants in the control group. Participants in the couples and women-only groups demonstrated a larger percentage change in intentions to use the device from baseline to follow-up than participants in the control group.

Consistent with the bivariate results, findings from the regression analyses show significantly different outcomes for participants assigned to the intervention groups and controls (Table 3, page 151). Compared with the controls, participants in either active intervention group were more likely to have used a female condom with their study partner and with all partners combined during follow-up (odds

Focusing on

both a woman

and hermale

partner is

efficacious in

increasing

female condom

use and inten-

tion to use

among hetero-

sexual couples

at risk for HIV

and other STDs. ratios, 4.1 and 3.6, respectively), used female condoms at higher rates with their study partners and with all partners during follow-up (incidence rate ratios, 4.3 and 3.7, respectively) and were more likely to intend to use the condom in the next 90 days (odds ratio, 2.2). However, there was no statistical difference in female condom use outcome expectancies. There were no significant differences between the women-only and couples intervention groups.

As expected, the baseline measures were significantly associated with their corresponding outcome measures at follow-up for almost all variables of interest. (The only exception is the number of times a female condom was used.) Gender and HIV status were not significantly associated with any outcome.

\section{DISCUSSION}

This study is the first clinical trial to demonstrate the efficacy of a relationship-based intervention at promoting female condom use among long-term heterosexual couples, and to test competing strategies for introducing the device. Our findings demonstrate that focusing on both a woman and her male partner is efficacious in increasing female condom use and intention to use among heterosexual couples at risk for HIV and other STDs. The findings for the womenonly group are consistent with results of other female condom intervention trials targeting women individually. ${ }^{21}$ The findings that both active interventions increased female condom use and use intentions add to the literature by offering two efficacious methods for promoting the device, one of which incorporates a woman's main male sexual partner.

Consistent with the principal outcomes of the parent study, ${ }^{22}$ the results of this study demonstrated no significant differences in outcomes between participants in the couples group and participants in the women-only group. We offer several possible explanations for these findings. First, all active intervention content was identical, with both groups focusing on the intimate relationship. Even in womenonly sessions, the relationship, and compromise between partners in risk reduction activities, was emphasized. Practicing communication, negotiation and condom skills aimed at cooperative risk reduction to strengthen the relationship, even without the partner present, may have been the key to the success of the intervention. A second potential factor is self-selection: Recruitment of females, who then recruited male partners, may have biased the sample toward includ- ing females who are comfortable discussing STD preventive behaviors with their partners and toward male partners who are highly motivated to engage in such behaviors and to use female condoms. Third, attendance was higher in the women-only group than in the couples group, and additional exposure may have facilitated greater improvement with respect to sexual risk behavior. Finally, the intervention promoted use of a hierarchy of risk reduction strategies, in which women and couples may adopt alternative strategies to male or female condom use. ${ }^{23}$ One suggested alternative was "negotiated safety," the option of agreeing to mutual monogamy or to use of barrier protection with casual partners only, following HIV testing. ${ }^{24}$ A purer test of outcome differences would have included an intervention that offered only the choice of male or female condoms, or perhaps female condoms alone, rather than a safer-sex hierarchy. Future research on strategies for introducing the female condom needs to consider ways to more carefully control for alternative method choices.

The increase in ever-use of a female condom from baseline to follow-up suggests that there were many first-time users among participants. This is consistent with findings of other studies and suggests a subsample of potential female condom adopters, ${ }^{25}$ who should be of particular interest in future research. Although Musaba et al. ${ }^{26}$ found that on average, among participants counseled to use either male or female condoms, female condoms were used in $24 \%, 27 \%$ and $23 \%$ of coital acts during three-, six- and 12-month follow-up, most longitudinal studies indicate that adopters of the female condom may use the device only for a short time, or use it with decreasing frequency over time. ${ }^{27}$ Further research is needed to identify these female condom adopters, to more effectively target those women and men who may be most receptive to using this method. Additional research to identify effective strategies to promote adoption and long-term use among couples is also needed.

The finding that participants in both active groups reported a relatively high intention to use the device within the next 90 days carries important implications. This finding is consistent with earlier ones suggesting that having an opportunity to become familiar with and use the device may facilitate more comfort with it and enhance intentions for use. ${ }^{28}$ Despite poor response to the device in the general press over the past decade, ${ }^{29}$ its introduction to couples, at least among our sample, is still being met with enthusiasm, interest and intention to use. Researchers may need to examine additional external factors, including availability and accessibility, as potential barriers to initiation and sustained use of the device.

Artz and colleagues ${ }^{30}$ found that among women in STD clinics who received a skill-based introduction to the female condom with take-home materials (including a motivational video to show their male partners), $79 \%$ tried the device at least once. In the present study, the control group watched a video on female condom insertion and received some education about the device, but the outcome effects were sig- 
nificantly greater in the active intervention groups. More research is needed to determine if outcomes are improved when those receiving individualized health education are given motivational or educational videotapes of female condom demonstrations to share with their partners.

Our findings must be considered in light of the following limitations. The study had a relatively small sample, data were self-reported and did not include biological outcomes on STDs, and the follow-up period was short. (We conducted a 12-month follow-up with the women, but were unable to do so for their male partners because of funding limitations.) The 90-day recall period, although standard for STD clinical trials, may have challenged the participants' ability to respond accurately. Study designs incorporating longer follow-up periods with larger samples and shorter recall periods, may produce stronger findings regarding promotion of female condom use among couples. The females in this study recruited their male partners, which may have led to a sample of self-selected male partners. Also, participants in the control group were not given free female condoms, as the active intervention participants were, but rather were advised about where they could them obtain for free. Because the mean number of female condoms used by participants was small, findings may have been influenced by participants' access to the method. However, although active intervention participants could have received up to 18 female condoms by attending all six sessions, these condoms may well have been used prior to the 90-day follow-up phase, upon which the data are based. Further, nonsignificant mean increases in female condom use reported by controls suggest that this group did access female condoms. Future designs must equalize both the number of devices and the time frame for which devices are made available to participants across groups. Outside of clinical trials, limited accessibility and availability of female condoms remains a significant barrier to use and uptake.

Until safe, efficacious and approved microbicides are widely available as an STD risk reduction method for women and their male partners, the female condom is a critical method, of empirically demonstrated effectiveness, and should be more widely promoted. Couple-based approaches, and increased opportunities to involve male partners in device use, should continue to be explored. Efforts must continue to develop innovative female condom promotion strategies and test them in rigorous trial designs. Research should target not only how best to introduce the device to individual women, men and couples, but how best to promote sustained use of the device. Although lack of availability and accessibility of the female condom are different issues from individual promotion strategies, ${ }^{31}$ simultaneous efforts must be made to increase availability and accessibility as a key to sustained use of the device.

\section{REFERENCES}

1. Ehrhardt AA and Exner TM, Prevention of sexual risk behavior for HIV infection with women, AIDS, 2000, 14(Suppl. 2):S53-S58; El-Bassel $\mathrm{N}$ et al., HIV prevention for intimate couples: a relationship-based model, Families, Systems and Health, 2001, 19(4):379-395; and Musaba E et al., Long-term use of the female condom among couples at high risk of human immunodeficiency virus infection in Zambia, Sexually Transmitted Diseases, 1998, 25(5):260-264.

2. World Health Organization, The Female Condom: A Review, Geneva: World Health Organization, 1997; Cecil H et al., The female condom: what we have learned thus far, AIDS and Behavior, 1998, 2(3):241-256; and Hoffman S et al., The future of the female condom, Perspectives on Sexual and Reproductive Health, 2004, 36(3):120-126.

3. Feldblum PJ et al., Female condom introduction and sexually transmitted infection prevalence: results of a community intervention trial in Kenya, AIDS, 2001, 15(8):1037-1044; French PP et al., Useeffectiveness of the female versus male condom in preventing sexually transmitted disease in women, Sexually Transmitted Diseases, 2003 , 30(5):433-439; and Fontanet AL et al., Protection against sexually transmitted diseases by granting sex workers in Thailand the choice of using the male or female condom: results from a randomized controlled trial, AIDS, 1998, 12(14):1851-1859.

4. Cecil H et al., 1998, op. cit. (see reference 2); Hoffman S et al., 2004 , op. cit. (see reference 2); and Fontanet AL et al., 1998, op. cit. (see reference 3).

5. Hoffman S et al., Female-condom use in a gender-specific family planning clinic trial, American Journal of Public Health, 2003, 93(11):18971903; Artz L et al., Effectiveness of an intervention promoting the female condom to patients at sexually transmitted disease clinics, American Journal of Public Health, 2000, 90(2):237-244; Stein Z et al., Safer sex strategies for women: the hierarchical model in methadone treatment clinics, Journal of Urban Health, 1999, 76(1):62-72; and Witte SS et al., Predictors of female condom use among women exchanging street sex in New York City, Sexually Transmitted Diseases, 2000, 27(2):93-100.

6. Musaba E et al., 1998, op. cit., (see reference 1); and Macaluso M et al., Female condom use among women at high risk of sexually transmitted disease, Family Planning Perspectives, 2000, 32(3):138-144.

7. Hoffman Set al., 2004, op. cit. (see reference 2).

8. World Health Organization, 1997, op. cit. (see reference 2); and Hoffman S et al., 2004, op. cit. (see reference 2).

9. El-Bassel N et al., Long-term effects of an HIV/STI sexual risk reduction intervention for heterosexual couples, AIDS and Behavior, 2005, 9(1):1-13; and El-Bassel N et al., The efficacy of a relationship-based HIV/STD prevention program for heterosexual couples, American Journal of Public Health, 2003, 93(6):963-969.

10. El-Bassel $\mathrm{N}$ et al., 2001, op. cit. (see reference 1); El-Bassel $\mathrm{N}$ et al., 2005 , op. cit. (see reference 9); El-Bassel N et al., 2003, op. cit. (see reference 9); and Witte SS et al., Recruitment of minority women and their main sexual partners in an HIV/STI prevention trial, Journal of Women's Health, 2004, 13(10):1137-1147.

11. Straus MA et al., The Revised Conflict Tactics Scales (CTS2): development and preliminary psychometric data, Journal of Family Issues, 1996, 17(3):283-316.

12. Witte SS et al., 2004, op. cit. (see reference 10).

13. New York City Department of Health and Mental Hygiene, For Women Only: What Women Can Do to Protect Themselves from AIDS, Albany, NY: New York State Department of Health, 1997.

14. Witte SS et al., 2000, op. cit. (see reference 5).

15. Schafer JL, Analysis of Incomplete Multivariate Data, London: Chapman \& Hall, 1997; and Rubin DB, Multiple Imputation for Nonresponse in Surveys, New York: John Wiley \& Sons, 1987.

16. Royston P, Multiple imputation of missing values: update, Stata Journal, 2005, 5(2):118-201.

17. Gardner W, Mulvey EP and Shaw EC, Regression analyses of counts and rates: Poisson, overdispersed Poisson, and negative binomial models, Psychological Bulletin, 1995, 118(3):392-404.

18. Koepsell TD et al., Data analysis and sample size issues in evaluations of community-based health promotion and disease prevention programs: a mixed-model analysis of variance approach, Journal of Clinical Epidemiology, 1991, 44(7):701-713; and Zhou H and Weinberg $\mathrm{CR}$, Potential for bias in estimating human fecundability parameters: a comparison of statistical models, Statistics in Medicine, 1999 , 18(4):411-422. 
19. Cochran WG and Cox GM, Experimental Designs, second ed., New York: John Wiley \& Sons, 1992

20. Voluntary HIV-1 Counseling and Testing Efficacy Study Group Efficacy of voluntary HIV-1 counselling and testing in individuals and couples in Kenya, Tanzania, and Trinidad: a randomised trial, Lancet, 2000, 356(9224):103-112; Dolezal C et al., Sexual risk behavior changes among HIV+ and HIV-female injecting drug users over 4 years, Women $\&$ Health, 1998, 27(4):1-17; and Dolezal C et al., Longitudinal changes in sexual risk behavior among HIV+ and HIV- male injecting drug users, American Journal of Drug and Alcohol Abuse, 1999, 25(2):281-303.

21. Hoffman S et al., 2003, op. cit. (see reference 5); Kalichman SC, Williams E and Nachimson D, Brief behavioral skills building intervention for female controlled methods of STD-HIV prevention: outcomes of a randomized clinical field trial, International Journal of STD E AIDS, 1999, 10(3):174-181; and Van Devanter N et al., Effect of an STD/HIV behavioral intervention on women's use of the female condom, American Journal of Public Health, 2002, 92(1):109-115.

22. El-Bassel N et al., 2005, op. cit. (see reference 9); and El-Bassel N et al., 2003, op. cit. (see reference 9).

23. Gollub EL et al., A randomized trial of hierarchical counseling in a short, clinic-based intervention to reduce the risk of sexually transmitted diseases in women, AIDS and Behavior, 2000, 14(9):1249-1255; Latka $\mathrm{M}$ et al., Male-condom and female-condom use among women after counseling in a risk-reduction hierarchy for STD prevention, Sexually Transmitted Diseases, 2000, 27(8):431-437; and Stein Z et al., 1999, op. cit. (see reference 5).

24. O'Leary A, Preventing HIV infection in heterosexual women: what do we know? what must we learn? Applied and Preventive Psychology, 1999, 8(4):257-263.

25. Musaba E et al., 1998, op. cit. (see reference 1); Artz L et al., 2000, op. cit. (see reference 5); Gollub EL et al., 2000, op. cit. (see reference
23); Kalichman SC, Williams E and Nachimson D, 1999, op. cit. (see reference 21); Stein Z et al., 1999, op. cit. (see reference 5); and Sly DF et al., Factors associated with the use of the female condom, Family Planning Perspectives, 1997, 29(4):181-184

26. Musaba E et al., 1998, op. cit. (see reference 1).

27. Ibid.; Hoffman S et al., 2003, op. cit. (see reference 5); and Padian $\mathrm{N}$ et al., Choice of female-controlled methods in Northern California paper presented at the 127th meeting of the American Public Health Association, Chicago, Nov. 7-11, 1999

28. Cecil H et al., 1998, op. cit. (see reference 2); Artz L et al., 2000, op. cit. (see reference 5); Kalichman SC, Williams E and Nachimson D, 1999, op. cit. (see reference 21); Witte SS et al., Acceptability of the female condom among women exchanging street sex in New York City, International Journal of STD \& AIDS, 1999, 10(3):162-168; El-Bassel N et al., Correlates of intention to use the female condom among women on methadone, Women's Health Issues, 1998, 8(2):112-122; and Gollub EL, Stein Z and El-Sadr W, Short-term acceptability of the female condom among staff and patients at a New York City hospital, Family Planning Perspectives, 1995, 27(4):155-158.

29. Kaler A, The female condom in North America: selling the technology of empowerment, Journal of Gender Studies, 2004, 13(2):139-152.

30. Artz L et al., 2000, op. cit. (see reference 5).

31. Hoffman S et al., 2004, op. cit. (see reference 2); and French PP et al., 2003 op. cit. (see reference 3 ).

\section{Acknowledgment}

This study was supported by National Institute of Mental Health grant MH57145.

Author contact: ssw12@columbia.edu 